\title{
Study on the Martial Spirit of Qin People from the Qin Empire
}

\author{
Yingqin Xiong \\ Language and Culture Communication Institute \\ Shangluo University \\ Shangluo, China 726000
}

\begin{abstract}
The serial epic "the Qin Empire", produced after a dozen years of aborative and hard experience, is a vivid portrayal of the social life of the Qin people, which highlights the Qin people's martial spirit. Militarism is the spiritual power of the Qin people to grow up and also the supporting power of the Qin Dynasty to establish the Qin empire and unify China, and it clearly affects the Qin culture.
\end{abstract}

Keywords-"the Qin Empire"; Qin people; militarism; aggressive

\section{INTRODUCTION}

"It's time to sweep off the six states, political or diplomatic struggle is rigorous in the raging west wind", a song of "rise" is finally performed in the early 2017 , of which each sentence brings people with deep emotion, such as "valiant Qin people, whether young or old, go on the battlefield for national calamity", "cyclone blows through the hills, only the people lie in the grass survived", " from generation to generation, Qin's brilliance will light each family's windowsill". Watching the Qin Empire, we are moved by the Qin people who are full of courageous and upright heroism, admire their common character of perseverance among the emperors and subjects in the successive dynasties and are convinced of their martial and aggressive spirit.

In recent years, some scholars are studying the Qin people's martial spirit from the perspective of Book of Songs . Qin's Style, and the article Qin people's Martial Spirit by Liu Fang and Ren Xiaofeng discussed the formation and characteristics of Qin people's martial spirit and its role [1]. Militarism is the spirit power of Qin people to make aggression and strive for prosperity, which is the Qin people's courageous and upright style reserved after a long history, so this paper attempts to interpret the Qin people's martial spirit in the three aspects of Qin people's martial tradition, martial custom and aggressive spirit from the Qin Empire.

\section{MiLITARISM IS THE FOUNDATION OF THE QIN EMPIRE TO BE ESTABLISHED}

Huainanzi · Summary says, "The style of Qin state is rapacious, acrid and powerful, ingrate and snobbish.[2]" The Qin Empire repeatedly referred that "Qin is a state like a tiger and a wolf", and the reason why he is daunting, is Qin people's brave and sturdy action as well as their strong fighting strength.

Fund project: Shangluo University scientific research project $15 \mathrm{sky} 028$.
On the Qin people "good at brave and hardy struggle", Wang Guijun thinks that Qin people is "independent, martial and modest[3]", which shows that the Qin people advocate military force. In fact, the habit of Qin people for warrior has a long history, and it should be relevant with their traditions.

\section{A. The Tradition of A Country to Be Established by Military Force}

It is said that the Qin people are originally from the eastern nation, and about in the Mu Wang period of the Western Zhou Dynasty moved from the southwest of Shanxi to the eastern part of Gansu, guarding the western border for the royal family of Zhou. In Longyou, they repeatedly struggled with the local Rong people, and gradually developed through about two hundred years of painstaking effort. Till Qin Xiang Gong was conferred as the feudal prince after making contributions in escorting Zhou Ping Wang for eastern transfer, the state is founded. Qin Wen Gong went over Longban to build the capital, and then began to enter the broad Weihe River Plain. Qin Wu Gong further expanded the territory to the eastern part of Guanzhong, and set counties to solid national strength. During the reign of Qin De Gong, the capital was moved to Yongcheng, and then Yongcheng was taken as the capital of Qin for three hundred years. During the reign of Qin Mu Gong, Qin destroyed Liang and Rui to expand the realm to the Yellow River in the east, and then annexed many small states of Rong and Di in the northwest. "Opened thousands of miles, then dominated Rong in the west", and eventually became one of the "Five Hegemons in the Spring and Autumn Period". During the period from Qin Feizi was conferred as dependency "town of Qin" to Qin Mu Gong dominated in Xiqi, Qin people experienced a lot of hardships. The rough living environment and the long-time arduous struggle against Rong and Di, not only build up Qin people's robust, plain and martial quality, but also contributed to the spirit tradition of advocating martial force, tenacity and hard work.

\section{B. Reinforcement of the Legalist School Thought}

The Qin Empire tells about the history and story from the end of Qin Xian Gong period to the time of Qin Wang Zheng unifying the world, and it is the most wonderful part in the history of near 800 years that Qin developed from a western small state into a powerful chief of the princes of the Spring and Autumn period and then dominated the world. From the third year of Xiao Gong period (359 BC) and the Shang 
Yang's political reform was carried to the previous day of reunification of the six states $(221 \mathrm{BC})$, the legalist school thought has dominated in Qin state for more than 130 years, and if adding the 15 years after the reunification, it has been up to one and half a century. After more than a hundred years of domination, the legalist school thought has penetrated into the Qin's politics, economy, culture and other social aspects.

The Disintegration of the Qin Empire talks about that under the strong support of the Qin Xiao Gong, the Daliangzao Wei Yang (called Shang Yang after conferred with the Shangyu land) implemented a grand and spectacular reform movement, of which a series of legalism-guided laws and rules and decrees followed and the agricultural war policy was also carried out. Since then, the Qin people ended the previous way of life, farming and combating as well as the related worship and prayer become the important content of life; "war" has become the daily conversation topic, and even relatives and friends will say "service imposed, a war can begin" when they meet, so that "people will congratulate it when hearing a war; sing the song of war in their everyday life [4]". In this regard, the scholar Yang Jing has incisively pointed out: "This is essentially advocating a culture of "delighting in war" and "attaching importance to war", which is specifically presented by "facilitating war in economy, intensifying war in system, advocating war in policy, worshipping war in fashion and concept and delighting in war and attaching importance to war in mindset and values [5] "

On Qin people's attitude on the war, The Book of Lord Shang records: "people treat war like a hungry wolf seeing the meat, and then the war is helpful for people. All that are fought must be that loathed by people. The man is able to call on the people for fighting is the king. As the people of a strong country, father hand down to his son, elder brother to young brother, wife to her husband, all say: no win, no return. [6]" At that time, "Han Feizi wrote in the $W u D u$ according to what he saw and heard in the Qin state: for the people in the state, what they talk about must be compliance of rules and laws, what they do must be successful and effective, who are brave must join the army and go into battle. So if there is no war, the state must be rich, and if there is a war, the state must have strong and powerful military force.[7]" Thus, we know, the thought of "delighting in war and attaching importance to war" carried out in Qin's political reform further strengthens the Qin people's concept of advocating military, encourages and cultivates the Qin people's habits of militarism.

\section{Militarism Is The QIN PeOPle's Social Customs}

By reading the history of the Qin state, or by watching the Qin Empire, we can find that militarism is a kind of Qin's social customs, which is mainly reflected in the followings:

\section{A. The State Attaches Importance to Martial Capability}

First, for the choice of the heir to the throne, the Qin in the Spring and Autumn period did not strictly follow the "system of the eldest son of emperor with his first legal wife inheriting the throne" under the patriarchal system but "chose the bold and powerful to be the king [8]"; and there is the tradition in Qin state that the man of unusual strength can be appointed as high-ranking military officer. During the Spring and Autumn Period, the well-known Hercules Du Hui in the Qin state often led the army to perform foreign war; During the Warring States period, the rulers of the Qin state still love the people of extraordinary force, who can be regarded or appointed senior officials or granted high government pay whether in the Qin state or the six states. Such as Qin Wu Wang himself has a liking for martial arts and often "raising Ding for the play"; during the period of his reign, the famous Hercules such as Ren Bi, Wu Huo and Meng Shuo all acted as senior officials, of whom Ren Bi still acted as prefecture chief of Hanzhong in the period of Qin Zhao Wang. At that time such a proverb was popular in Qin state: "the strongest is Ren $\mathrm{Bi}$ and the wisest is Chu Li".

Second, Qin has numerous talents among the six states, of which the number of military talents is most. During the Spring and Autumn period, there are Gongsun Zhi, Bai Yibing, Xi Qishu, Meng Mingshi etc; during the Warring States period, there are Shang Yang, Zhang Yi, Gongsun Yan, Sima Cuo, Yue Chi, Wei Zhang, Gan Mao, Du Shou, Bai Qi, Ren Bi, Lyu Li, Meng Wu, Meng Ao, Meng Tian, Wei Sili, Wang Bao, Sima Geng, General Liao, Wei Liao, Huan Qi, Wang Jian, Wang Ben etc. By watching the Qin Empire, we will easily find that these persons render meritorious service and become famous both in the army control and the battle for the Qin state and in the cause of Qin unifying six states, which is enough to prove that the rulers of Qin all attach important attention to the martial capacity in the selection of talent.

\section{B. The Society Worships Heroes and Warriors}

Qin people always worship the heroes and warriors, and Qin state also has the fashion of militarism. In Qin people's mind, most of the heroes are those persons who make great contribution to the state and the nation, especially those allpowerful heroes and warriors galloping across the battlefield. Historical Records - Qin Dynasty records that Qin Mu Gong died, and the famous senior official Zi Yushi's three children were be buried alive with him; Qin people all were sad for $\mathrm{Zi}$ Yushi and wrote the poem Oriole to express their sadness, which uses the oriole on the thorn tree to imply the Zi Yushi's children should not be buried alive as sacrificial objects, because people think such a brave warrior should be alive for making more contributions to the Qin state.

Similarly, the "God of War" Bai Qi in the Rise of the Qin Empire had set up illustrious military exploits for sweeping off the six states, but he committed suicide by imperial order only because he did not accept Qin Zhao Wang's order to continue the attack to Zhao state after the war of Chang Ping between Qin and Zhao, and Qin people all also express their infinite feelings of mourning for the death of Bai Qi. In this regard, it is recorded in the Historical Records. Bai Qi Biography that after the death of Bai Qi, the Qin people pitied "died not for his crime, the whole home village offered sacrifice for him", later "the emperor Qin Shi Huang ascended the throne, thinking its achievement, and conferred his descendants a rank of nobility in Taiyuan" to assuage the people's anger. [9]. 


\section{MARTIAL SPIRIT IS CARRIED FORWARD IN AN AGGRESSIVE AND STRUGGLING ERA}

Qin people's martial spirit originated from the martial tradition of Qin nation, and based on the Qin people's social customs, it is carried forward in an aggressive and struggling era. Because the Qin history, Qin people must be aggressive for survival, without other choice. Generally, as a small border state in the Zhou Dynasty, Qin developed into the hegemon in the West Rong and then in the Central Plains, and eventually achieved the unification of China, which is attributed to the successive military conquest and innovation for years, rather than the moral articles and conservative tradition.

\section{A. Aggression Is the Trend of the Times}

During the Spring and Autumn period and the Warring States period, a group of independent feudual lords existed together, continuously vying for supremacy, and the military struggle became their basic means to seek for survival and development. As the saying goes, "there is no moral war during the Spring and Autumn period; the Zhou dynasty declined, the attack and merger among vassal states became frequent and ordinary. The vassal states all very depended on the military strength to make survival or compete for domination. During the Warring States period, the war scene is crueler and more intense, just as the so-called "fighting for land, the killed people will be full of the whole field; fighting for city, the killed people will full of the whole city. [10]" After the long-term merger and competition, finally seven states of feudal lord system are reserved. However, the common existence of seven states is only a short situation of counterbalance after the long-term war. With the rise of the "strong Qin", the six states in the east had doubled pressure, and gradually the trend "six-state federation for resisting Qi" formed. The situation of "six-strong against one-strong" brought the Qin people severe challenges, which forced Qin to decide they must advance towards to the east. If failed, they will go back to the west, but the Qin people who had developed by the long-term hard work of their ancestors are never willing to go back, so unifying China becomes their ultimate goal, and the aggressive and struggling spirit is further inspired and carried forward.

\section{B. Aggression Is Inevitable for Qin People to Change the Geographical Environment}

During the seventh year of Qin Xiang Gong period (711 BC), Qin "dispatch forces to rescue the Zhou dynasty, and made great merits and achievements", so was granted the land in the west of Qi. Since Xiang Gong was conferred the land and the lord, Qin nominally occupied the western Qi, but the Rong and Di in the surrounding area often made troubles and invasion, so Qin people had no choice but to launch battle for guarding their territory. Till the Qin Wen Gong "sending forces to crusade against Rong", Qin finally consolidated the foundation of its state. Geographically, the long-term living together with Rong and Di and the long-term struggling, make Qin people form the cultural spirit rich in creation and aggression during the collision and integration with Rong and $\mathrm{Di}$ culture, at the same time they inherit the Zhou culture. The bad living environment, especially the bad natural conditions, such as inferior soil, deficient materials and harsh climate, decide the Qin people's characteristics of advocating force and being good at fighting. At the same time, the idea to change the harsh natural geographical environment and the reality of living together with Rong and Di both become the power of Qin people to make incessant creation and innovation, advance toward the east.

\section{CONCLUSION}

Militarism is the prominent spiritual features of Qin people, and it is the ultimate force of Qin people to develop from a weak state into a strong state and eventually establish a unified feudal empire. The historical tradition of setting the foundation and establishing a state by force, the agricultural war policy implemented after Shang Yang reform, the wide respect for heroes and warriors in the whole society, the trend of aggressive era and the recognition of emperors for military forces, all promote the Qin people to form their fiery and forthright, brave and persistent character through many years of campaign for unifying China, and achieve the distinctive martial and aggressive spirit in Qin culture. The way of becoming a strong country and the dream of unifying a country in the Qin Empire move every audience with patriotic feelings and enterprising aspirations, which is significant for the great rejuvenation of Chinese nation today.

\section{REFERENCES}

[1] Liu Fang. Qin People's Martial Arts [A] .Chinese Pre-Qin History Society. Research on Zhou-Qin Social and Cultural - to Commemorate the 20th Anniversary of the Establishment of China's Pre-Qin History Academy, Collection of Academic Symposium Papers [C]. China's PreQin History Academy : 2002: 17

[2] Chen Guangzhong. Translation Note of Huainanzi. [M]. Beijing: Zhonghua Book Company, 2012: 1143

[3] Wang Guijun. The Book of Date --- On the Custom of Early Qin [J]. Museum of Cultural Relics, 1988 (4): 34

[4] Shi Lei. The Book of Lord Shang - Rewards and Punishments [M]. Beijing: Zhonghua Book Company, 2011: 134-135

[5] Yang Jin. The Impact of Style and Custom Change on Qin Culture[J] .Xi'an: Journal of Xi'an University of Finance and Economics, 2008 (1): 44

[6] Shi Lei. The Book of Lord Shang · Planning and Policy [M]. Beijing: Zhonghua Book Company, 2011: 136

[7] Zhang Jue. Translation Note of Han Feizi [M]. Shanghai: Shanghai Ancient Books Publishing House, 2016: 791

[8] Liu Mei, Hao Meimei. On the Military Characteristics of Qin Culture and Its Reasons [J]. Anhui: Journal of Wuhu Institute of Technology, 2006 (1): 8-10.

[9] Sima Qian. Historical Records [M]. Jilin: Northern Women and Children's Publishing House, 2004: 345-346

[10] Wang Xianqian. Xunzi Commentaries[M]. Beijing: Zhonghua Book Company, 2012: 279. 